\title{
IMPROVED TRAWLING SETUP FOR SAMPLING PELAGIC JUVENILE FISH COMMUNITIES IN SMALL INLAND BODIES OF WATER
}

\author{
Tomáš JŮZA*, Zuzana SAJDLOVÁ, Martin ČECH, Vladislav DRAŠTÍK, Luboš KOČVARA, \\ Michal TUŠER, and Jan KUBEČKA
}

Biology Centre of the Czech Academy of Sciences, Institute of Hydrobiology, České Budějovice, Czech Republic

\begin{abstract}
Jůza T., Sajdlová Z., Čech M., Draštík V., Kočvara L., Tušer., M, Kubečka J. 2018. Improved trawling setup for sampling pelagic juvenile fish communities in small inland bodies of water. Acta Ichthyol. Piscat. 48 (1): 105-108.
\end{abstract}

\begin{abstract}
Trawling juveniles is an effective method to estimate 0+ fish assemblages in inland bodies of water. Trawlers are usually moved between bodies of water by ground transport, which restricts the size, weight and type of the equipment able to be transported, and as such do not always come equipped with machinery for trawl operation. Having to lift the trawl onto the deck of the trawler after each tow also makes small-scale juvenile trawling time-consuming and personnel intensive and deep water trawling is especially hard work. This study introduces a new two-boat setup for continuous trawling that enables faster and easier operation of the trawl, even in deep water layers, and more accurate distance and depth measurements.
\end{abstract}

Keywords: fixed-frame trawl, manipulation boat, two-boat setup

The study of juvenile communities is a key requirement to understanding fish communities as a whole. Knowledge of yearly recruitment is very important to the prediction of future fish stocks, and the juvenile community also reflects the adult fish community and indicates the success of the natural reproduction (Jurajda et al. 2010). Trawling is a common sampling method for pelagic larvae and early juveniles in lakes and reservoirs (Čech et al. 2007, Jůza et al. 2012) and in the sea (Methot 1986, Itaya et al. 2007), and at night, it has been an effective quantitative method without significant fish avoidance reactions that provided reliable information about pelagic juvenile communities (Jůza and Kubečka 2007, Jůza et al. 2010). Quantitative sampling in pelagic areas is an extremely important prerequisite for an unbiased picture of the juvenile community. To sample early fish juveniles during spring or older juveniles during late summer, fixed framed trawls, measuring $2 \times 2 \mathrm{~m}$ or 3 $\times 3 \mathrm{~m}$, are convenient sampling tools (Jůza and Kubečka 2007, Jůza et al. 2010). These trawls are towed behind a motorboat with the trawl kept at a required depth by the buoy (one-boat setup) and after each tow, the net must be manually moved toward the boat and lifted onto the deck for all catch to be released from the net (Fig. 1a). The net is again set into the water and after straightening the towing rope, another tow can start. The tow itself takes 10 min and the entire operation, including setting the net, the actual tow, lifting the net from the water, and processing the catch can take or exceed $20 \mathrm{~min}$, especially in the case of deep-water tows. Trawlers must be equipped with heavy machinery for fast and comfortable operations (Itaya et al. 2001) and in its absence, the lifting aboard of a frame trawl is a difficult work. At least three, but preferably four, people are required to operate the trawl (three people for setting and lifting the trawl into and from the water and one for operating the boat). The motorboats used in small bodies of water such as reservoirs, small lakes, and post-mining lakes are rarely equipped with the necessities for comfortable trawling because they are transported by roads and cannot exceed the size and weight limits for ground transport. To lower the costs of complex fish stock surveys, boats used for trawling have multiple purposes and are not fully adapted for trawling. This fact makes the one-boat setup trawling time consuming and demanding in terms of manpower.

The two-boat trawling setup for juvenile fish was introduced in 2015 to address the disadvantages of the one-boat setup. The new setup adds a second manipulation boat that also serves as a buoy (Fig. 1b). One end of the wire is fixed to the upper trawl frame and the other end is fixed to the removable hand winch attached to the manipulation boat (Fig. 1b). The trawl, together with the manipulation boat, are towed by a $100 \mathrm{~m}$ long rope by the trawler. Therefore, the crew of the manipulation boat is still in direct connection with the trawl. The cod end of the trawl is connected to the manipulation boat by the rope (Fig. 1b), so that after each tow the trawl is lifted

\footnotetext{
* Correspondence: Dr Tomáš Jůza, Biologické centrum AV ČR, v.v.i. Hydrobiologický ústav, Na Sádkách 7, 37005, České Budějovice, Czech Republic, phone: +420 387775 831, fax: number+420 385310 248, e-mail: (TJ) tomas.juza@seznam.cz, (ZS) zuzana@sajdl.info, (MC) carcharhinusleucas@yahoo.com, (VD) v.drastik@gmail.com, (LK)l.kocvara@seznam.cz, (MT)michal.tuser@gmail.com, (JK)kubecka@hbu.cas.cz.
} 
to the surface by a winch, the cod end is dragged to the boat by the rope and the catch is released. Compared to the previous one-boat setup, the main body of the trawl remains in the water below the second boat and is not dragged on board the trawler or the manipulation boat. Only the cod end with the catch is pulled out of the water onto the manipulation boat to remove the catch. In this improved setup, the trawl is set only once from the trawler (before the first tow) and the catch is released directly from the manipulation boat. As in a one-boat setup, four people are optimal for operating the two boat-trawling setup (two people on the trawler to operate the boat and the echosounder and two people on the manipulation boat to operate the trawl and process the catch). Walkie-talkies or light signals are used to inform the manipulation boat crew of the start and finish of the tow, and to inform the crew of the trawler of the catch processing and trawl preparation for the next tow.

To compare the time demands of both setups, we looked at trawling survey data from the exact same localities and depth layers in the Lipno Reservoir from 2010 (one-boat setup) and 2017 (two-boat setup). The $3 \times 3 \mathrm{~m}$ trawl with the mesh size of $6 \mathrm{~mm}$ knot to knot in the belly and $4 \mathrm{~mm}$ in the cod end was used in both surveys (for the detailed description of the trawl design see Jůza and Kubečka 2007). The Lipno Reservoir, on the Vltava River in Southern Bohemia, is a shallow wellmixed reservoir with a surface area of 4800 ha, maximum depth $22 \mathrm{~m}$, mean depth $6.5 \mathrm{~m}$, and total volume $306 \mathrm{mil}$. $\mathrm{m}^{3}$. The duration of individual tows between setups were compared by $t$-test (Statistica 10 software).

The main advantages and disadvantages of both setups are summarized in Table 1. Both methods require the same number of people, but a two-boat setup is faster to operate. A comparison of juvenile trawling performed in the same localities and depth strata in 2010 and 2017 revealed that the mean ( \pm standard deviation) total time per tow (10 min duration) was $15 \pm 2 \mathrm{~min}$ in 2017 but $23 \pm 4.1 \mathrm{~min}$ in 2010 (the difference was statistically significant, $t$-test $P$ $<0.001, t=7.98, \mathrm{df}=64)$. In each year, a total of 34 tows over two nights were done in the reservoir during pelagic juvenile surveys, and $4.5 \mathrm{~h}$ were saved by using the twoboat setup. The main time saving in the two-boat setup is the elimination of unnecessary lifting of the trawl onto the deck of the trawler after each tow. Because the trawl stays in the water and is operated from the manipulation boat at all times, the two-boat setup is also much less physically demanding. Lifting the relatively heavy trawl from the deeper water layers by a winch fixed to the manipulation boat is also much easier than lifting the trawl onto the deck of the trawler in a one-boat setup. Accurate measuring of the trawling distance is also very important because the

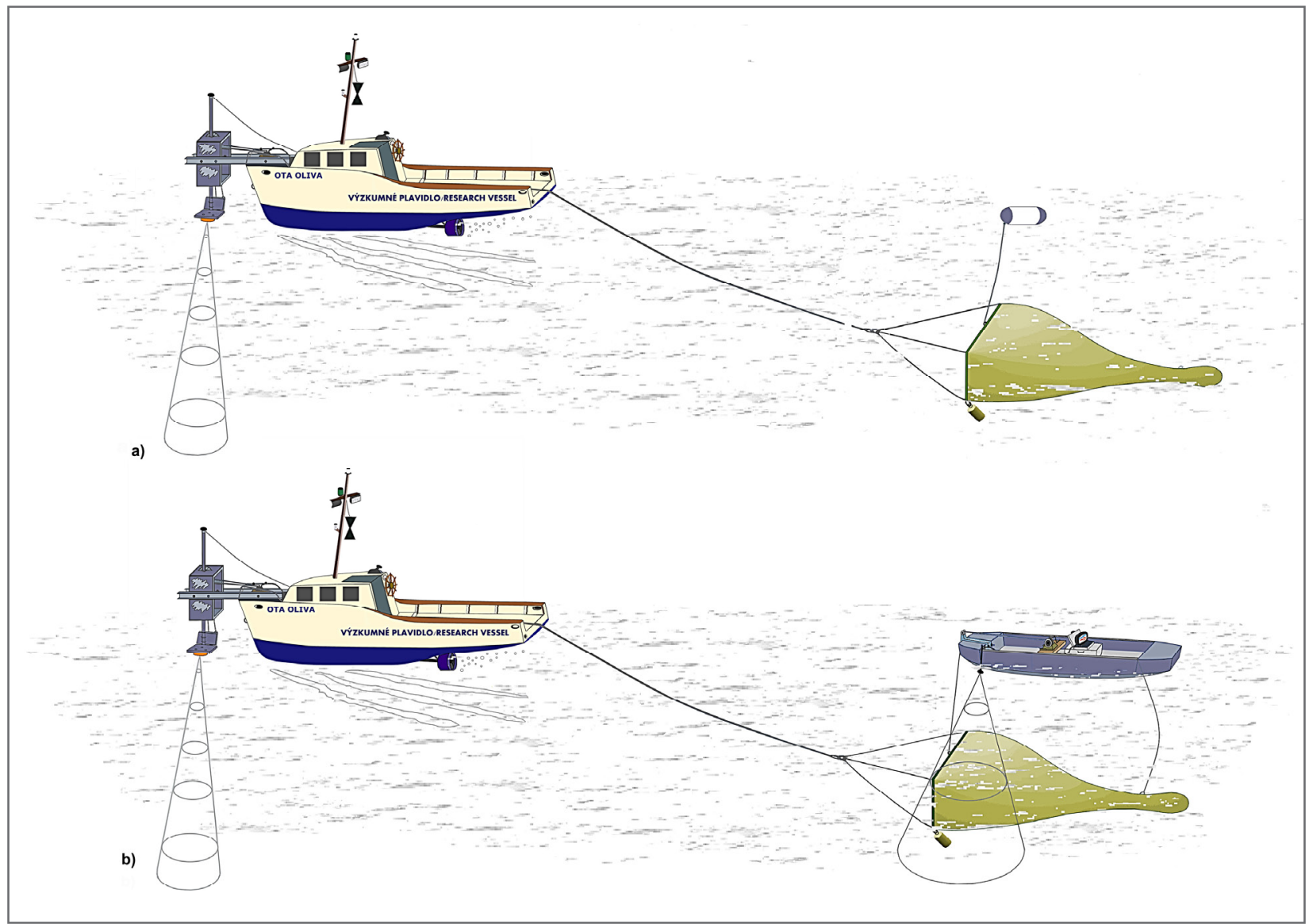

Fig. 1. One-boat setup (A) and modified two-boat setup (B) for fry trawling; the two-boat setup is with a flat bottomed boat instead of a buoy equipped with the hand winch for lifting the trawl from deeper layers and an echosounder for checking the depth of trawling 
Table 1 practical experience has shown that the resistance effect

The main advantages and disadvantages of one-boat and two-boat setups

\begin{tabular}{lll}
\hline \multicolumn{1}{c}{ Advantage/disadvantage } & One-boat setup & Two-boat setup \\
\hline People required (optimal) & 4 & 4 \\
Time required for one tow & $>20$ min & $<15$ min \\
Physical demand & High & Low \\
Trawl track measuring & Biased & Exact \\
Trawl depth checking & Difficult & Simple \\
Trawling close to the bottom & Dangerous & Trouble-Free \\
Crossing between tows & Simple & Difficult \\
Depth changing & Demanding & Simple \\
\hline
\end{tabular}

water volume sampled and exact catch per unit of effort (CPUE, catch per water volume sampled) are calculated based on this distance. During a one-boat setup, a GPS is situated on the trawler and track of the trawler is measured. Since the trawler moves on a slightly curved trajectory to minimalize its disturbing effect on fish, especially during surface tows, the track of the trawl is always shorter than the track of the trawler. Use of a two-boat setup enables measuring of the track directly from the manipulation boat, which is in exactly the same position as the trawl. The calculation of trawl CPUE is therefore more accurate than track measuring from the trawler.

Another advantage of the two-boat setup is the measurement of the real depth of trawling. Determination of depth in deep water trawling may be inaccurate and especially for deeper tows, the length of the rope between the trawl and the buoy does not correspond to the depth of trawling (Jůza et al. 2012). In a one-boat setup, a sophisticated and also expensive wireless system is necessary, where a sensor is fixed to the trawl and the depth of trawling is transmitted to the deck of the trawler. In a two-boat setup, the exact depth of trawling can easily be checked by a commonly used and inexpensive angler's echosounder, which is fixed to the manipulation boat. The iron frame of the trawl directly below the boat can easily be detected even by a simple echosounder. The two-boat setup offers another advantage if the echosounder finds that the trawl is not located at the required depth, its position in the water column can be easily changed by the winch. A two-boat setup also provides the possibility to sample very close to the bottom (in shallow tributary areas for example). The crew of the manipulation boat can check the distance between the lower trawl frame and the bottom, the trawl can be set, by winch, as close to the bottom as needed. Fish living close to the bottom can also be captured, which would not be possible in a oneboat setup. Without direct observations of the trawl by an echosounder in a one-boat setup, trawling in such shallow waters is dangerous because the net can possibly touch the bottom. This would usually mean the net getting stuck in the mud or on other obstacles.

Concern that the manipulation boat would cause too much resistance in the water when compared with the small float (i.e., the manipulation boat would be lifting the trawl up) may deter the use of the second boat, however, of a small manipulation boat is negligible and the boat is located just near the trawl. The vertical position of the trawl, below the manipulation boat, is facilitated by the considerable weight of the trawl frame $(40 \mathrm{~kg}$ approximately), its slow sampling speed $\left(4 \mathrm{~km} \cdot \mathrm{h}^{-1}\right)$ and by the steel wire connecting the trawl with the winch on the boat (low resistance). The disproportion between the depth of trawling and the length of wire was observed for tows deeper than $12 \mathrm{~m}$. In this case, some wire was added by a winch during the tow to keep the trawl at the required depth.

A two-boat setup is advantageous when one tow continues directly after another. If there are long crossings between tows, a one-boat setup is more convenient. When moving the boats between bodies of water, the cost of a two-boat setup increases slightly because of the need to move two boats. However, especially during the study of pelagic juvenile communities in freshwater lakes and reservoirs, when continuous trawling is possible and where a second manipulation boat is available, a twoboat setup saves a lot of time and manpower and makes juvenile trawling much more comfortable in comparison with a one-boat setup.

\section{ACKNOWLEDGEMENTS}

We thank Z. Prachař for help with the fieldwork, Mary Morris and Leslie Tse for English correction. The work was supported from ERDF/ESF project Biomanipulation as a tool for improving water quality of dam reservoirs (No. CZ.02.1.01/0.0/0.0/16_025/0007417).

\section{REFERENCES}

Čech M., Kubečka J., Frouzová J., Draštík V., Kratochvíl M., Matěna J., Hejzlar J. 2007. Distribution of bathypelagic perch fry layer along the longitudinal profile of two large canyon-shaped reservoirs. Journal of Fish Biology 70 (1): 141-154. DOI: $10.1111 /$ j.1095-8649.2006.01282.x

Itaya K., Fujimori I., Shiode D., Aoki I., Yonezawa T., Shimizu S., Miura T. 2001. Sampling performance and operational quality of a frame trawl used to catch juvenile fish. Fisheries Science 67 (3): 436-443. DOI: 10.1046/j.1444-2906.2001.00279.x

Itaya K., Fujimori Y., Shimizu S., Komatsu T., Miura T. 2007. Effect of towing speed and net mouth size on catch efficiency in framed midwater trawls. Fisheries Science 73 (5): 1007-1016. DOI: 10.1111/j.14442906.2007.01430.x

Jurajda P., Slavík O., White S., Adámek Z. 2010. Young-of-the-year fish assemblages as an alternative to adult fish monitoring for ecological quality evaluation of running waters. Hydrobiologia 644 (1): 89-101. DOI: 10.1007/s10750-010-0111-4

Jůza T., Čech M., Kubečka J., Vašek M., Peterka J., Matěna J. 2010. The influence of the trawl mouth opening size and net colour on catch efficiency during sampling of early fish stages. Fisheries Research $\mathbf{1 0 5}$ (3): 125-133. DOI: 10.1016/j.fishres.2010.03.010 
Jůza T., Frouzová J., Brämick U., Draštík V., Mrkvička Jůza T., Kubečka J. 2007. The efficiency of three T., Kubečka J. 2012. The vertical distribution of fish in the open water area of a deep temperate mesotrophic lake assessed by hydroacoustics and midwater fry trawls for sampling the freshwater pelagic fry community. Fisheries Research 85 (3): 285-290. DOI: 10.1016/j.fishres.2007.03.001

trawling. International Review of Hydrobiology 97 Methot R.D. 1986. Frame trawl for sampling pelagic (6): 509-525. DOI: 10.1002/iroh.201101440 juvenile fish. CalCOFI Reports 27: 267-278.

Received: 2 January 2018

Accepted: 2 February 2018

Published electronically: 31 March 2018 